increase upon being told that the child had eaten a few hours ago. I knew enough to realize that this was a bad thing! The surgeon and his assistant assured me that they would monitor my performance closely and I was not to be concemed. "Don't worry," they said.

I placed several layers of gauze on the appropriate frame, held it over the patient's face and began to drop ether onto the gauze. It seemed only a matter of minutes before the surgeon decided that the patient was ready. The surgery was started and soon the surgeon's hand was inside the patient's abdomen.

He complimented me on the excellence of the abdominal wall relaxation, but with that, he paused, as if he had had some second thoughts. Perhaps it was the blue colour of the blood that had disturbed him. He quickly asked me to look at the pupils of the patient's eyes. I recall that they were dilated and fixed.

I looked around in panic. No one was breathing, not the nurses, not the surgeon and his assistant, not me, but the patient's nostrils seemed to be flaring feebly. At the surgeon's demand, I had removed the mask and was running some oxygen into the patient's mouth using an "ether hook." The patient began to breathe more vigorously and his colour had slowly improved.

Everyone had now relaxed, everyone that is, but I. The surgeon continued the procedure and although I had replaced the mask I was too terrified to drop any more ether. In a few moments the patient awoke and began to vomit. "Put him down," the surgeon shouted. Somehow I did put him down - down to the earlier stage of near respiratory arrest and deep cyanosis, "Let him up," came the surgeon's demand. Again the patient emerged to the vomiting level. "Put him down," came the cry from the other side of the screen.

In this manner, with terror and with shouts of "put him down" and "let him up" we finally reached the end of the procedure. The results of this event may be summarized as follows:

(1) The child made an uneventful recovery.

(2) The parents thanked me for my expertise.

(3) The surgeon had me banned from the operating room.

(4) I vowed that I would never have anything to do with anaesthesia again.

God thought otherwise however, for in January of 1951, I left "country practice" and commenced a residency in anaesthesia at the St. Boniface General
Hospital under Dr. Marjorie Bennett. And it was there that I spent the next 25 years in the practice of anaesthesia. I shall always be sincerely grateful to have had the opportunity, indeed the privilege, to participate in the academic growth of our specialty in Manitoba and in the political development of anaesthesia in Canada.

My wife and I moved to Phoenix in 1976. Neither the pleasant weather, the favourable economics, nor the easy working conditions of a practice confined to outpatient anaesthesia will ever diminish the memory and pleasure of a quarter century spent in the practice of anaesthesia in the province of Manitoba.

Max Minuck MD

684, North 3rd Place,

Phoenix, Arizona 85012

\section{Rebreathing and the Bain circuit}

To the Editor:

I read with interest the paper by Spoerel (Can Anaesth Soc J 1983; 30: 148-54), the subsequent comment by Imrie and the reply by Spoerel (Can Anaesth Soc J 1983; 30: 679-81).

The debate concerning the place of the Bain system for spontaneous respiration continues unabated, and appears to centre on the definition and significance of any rebreathing that may be observed. Because both are so differently interpreted by numerous investigators, it has become difficult to compare the results of the various papers. Those, like Spoerel, who feel that there is a place for the Bain for spontaneous respiration argue that the rebreathing that is evident at the lower fresh gas flows employed for Mapleson A systems, is not significant. Others argue that the obvious rebreathing presents a potential risk to every patient. '

I have already commented elsewhere on the diffculty in measuring the end point at which rebreathing can be said to begin to occur. ${ }^{2}$ However, rebreathing must be said to be significant when, after exchanging one breathing system for another under identical conditions, a rise in both inspired and end-expired $\mathrm{CO}_{2}$ tensians is observed. By employing this technique in anaesthetised adult patients, I directly compared the efficiency of the 
Lack (modified Mapleson A), Magill (Mapleson A) and the Bain (modified Mapleson D) systems, ${ }^{3}$ and clearly showed the Bain to cause marked rebreathing compared to the other systems when employing a fixed fresh gas flow of $70 \mathrm{ml} \cdot \mathrm{kg}^{-1} \cdot \mathrm{min}^{-1}$. The minimum inspired $\mathrm{CO}_{2}$ tensions were $0.07 \mathrm{kPa}$, $0.33 \mathrm{kPa}$ and $3.74 \mathrm{kPa}$ respectively, while endexpired $\mathrm{CO}_{2}$ tensions were $6.43 \mathrm{kPa}, 6.93 \mathrm{kPa}$ and $7.55 \mathrm{kPa}$ respectively. Even if attempts were made by patients to compensate for this hypercarbia by increasing minute ventilation, the Bain caused a mean rise of $1.12 \mathrm{kPa}$ in end-expired $\mathrm{CO}_{2}$ tension compared to the Lack which, somewhat surprisingly, proved to be more efficient than the Magill.

What is indisputable from all the literature is that Mapleson D or E systems do not function as efficiently as Mapleson A systems for spontaneous respiration. The Lack, shown to be about 30 per cent more efficient than the Magill and three times more so than the Bain, ${ }^{3}$ should perhaps be recommended as the system of choice. However, the combination of the principles of both the Lack for spontaneous respiration and the Bain for controlled ventilation into one system would seem to be advantagcous. Such a system combining Mapleson A, D and $E$ principles has recently been described. ${ }^{4}$ Independent reports ${ }^{5,6}$ confirm that this new $\mathrm{ADE}$ system achieves its goal, is simple to use and allows ease of control of theatre pollution. For spontaneous respiration low fresh gas flows between 46 and 56 $\mathrm{ml} \cdot \mathrm{kg}^{-1} \cdot \mathrm{min}^{-1}$ were all that were required (3.2-4.0 litres $\min ^{-1}$ for a $70 \mathrm{~kg}$ subject) to prevent rebreathing. For controlled ventilation the ADE behaved identically to the Bain, ${ }^{6}$ normocarbia being maintained with a fresh gas flow of $70 \mathrm{ml} \cdot \mathrm{kg}^{-1} \cdot \mathrm{min}^{-1}$. This versatile system, available in both coaxial and non-coaxial forms, would therefore appear to offer a solution to the controversial use of the Bain circuit for spontaneous respiration, and eliminate further concern about high fresh gas flows, consequent operating room pollution and increased costs with the Bain during this mode of use.

\section{David Humphrey MBBS DA \\ Department of Physiology \\ University of Natal}

Durban, Natal, South Africa

\section{REFERENCES}

1 Byrick RJ. Respiratory compensation during spontaneous ventilation with the Bain circuit. Can Anaesth Soc J 1980; 27: 96-105.
2 Humphrey D. Rebreathing and the Bain circuit. Anesthesiology 1984; 60: 80-I

3 Humphrey D. The Lack, Magill and Bain anaesthetic breathing systems: a direct compurison in spontaneously breathing anaesthetized adults. Journal of the Royal Society of Medicine 1982; 75: 513-24.

4 Humphrey $D$. A new anaesthetic breathing system combining Mapleson $\Lambda, D$ and E principles: a simple apparatus for low flow universal use without carbon dioxide absorption. Anaesthesia, 1983, 38: $361-72$.

5 Dixon J, Chakrabarti MK, Morgan M. An assessment of the Humphrey ADE anaesthetic system in the Mapleson A mode during spontaneous respiration. Anaesthesia. In press 1984.

6 Shulman MS, Brodsky $J B$. The ADE system - a new anesthetic breathing system. Anesth. In press 1984.

\section{Complete endo- tracheal tube obstruction after nasotracheal intubation}

To the Editor:

We recently encountered a case in which the tracheal tube was obstructed completely by a dislodged inferior turbinate after nasotracheal intubation.

A 53-year-old woman was scheduled for drainage of paravertebral abscess and anterior arthrodesis for tuberculous infection of the thoracic spine. We chose nasotracheal intubation because long-term mechanical ventilation was anticipated following the operation. There was no history of pre-existing nasal disease.

After application of phenylephrine to the right nasal mucosa, intravenous diazepam, $10 \mathrm{mg}$, morphine, $40 \mathrm{mg}$ and succinylcholine $50 \mathrm{mg}$ was administered to facilitate laryngoscopy. Nasotracheal intubation was attempted using a generously lubricated Portex ID $8 \mathrm{~mm}$ endotracheal tube. Passage of the tube through the nares was not difficult.

Immediately after the placement of the tube into 